\title{
Iron Status in Preschool Children with Normal Hemoglobin, Egypt
}

\author{
Osama M. El-Asheer ${ }^{1 *}$ (D), Mary S. Naeem${ }^{1}$, Fardos H. Abd El Aal ${ }^{1}$, Madleen A. A. Abdou², Khalil Abdel Khalek Mohamed ${ }^{3}$ \\ ${ }^{1}$ Department of Pediatric, Assiut University Children Hospital, Asyut, Egypt; ${ }^{2}$ Department of Clinical Pathology, Assiut University \\ Hospital, Asyut, Egypt; ${ }^{3}$ Department of Pediatric, Faulty of Medicine, Cairo University, Cairo, Egypt
}

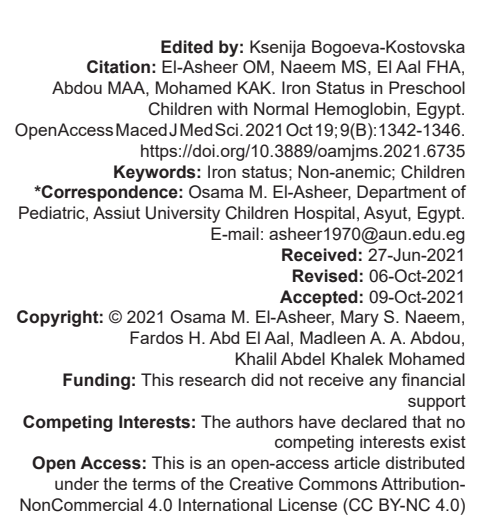

Abstract

BACKGROUND: Iron deficiency (ID) anemia remains a common cause of anemia in young children. However, the more significant than anemia itself is the ID without anemia that also adversely affect neurocognitive development and unfortunately some of these effects may be irreversible.

AIM: This study is a cross-sectional study aimed to asses iron status in preschool children with normal hemoglobin (Hgb) level attending Assiut University Children Hospital.

METHODS: The cross-sectional study including 68 apparently healthy children aged 1-6 years old during the period from January 1, 2015 to June 30, 2015, They were subjected to detailed history, physical examination, and the following laboratory investigations: Complete blood count, Serum iron, Total Iron Binding Capacity, Serum ferritin, and Transferrin saturation.

RESULTS: Low serum ferritin and low transferrin saturation were detected in $41.2 \%$ and $47 \%$ respectively of our studied children who have normal Hgb levels.

CONCLUSION: Normal Hgb doesn't exclude ID that should be screened in healthy children to prevent the possible long-term effects of ID on their cognation and mental development.

\section{Introduction}

Iron deficiency (ID) and ID anemia (IDA) continue to be of worldwide concern. Iron is the most common single nutrient deficiency among children in the developing countries [1]. In developed nations, despite marked decline in prevalence, IDA remains a common cause of anemia in young children [2]. However, the more significant than anemia itself is the more common ID without anemia that also adversely affect neurodevelopment and behavior and some of these effects may be irreversible [3]. Iron is a trace element that is essential for numerous cellular metabolic functions [4]. The body requires iron for the synthesis of its oxygen transport proteins, in particular hemoglobin (Hgb) and myoglobin and for the formation of heme enzymes and other iron-containing enzymes involved in electron transfer and oxidation-reductions [5].

Around $70 \%$ of the total body iron is in heme compounds (e.g. Hgb and myoglobin), $29 \%$ is stored as ferritin and hemosiderin, $<1 \%$ is incorporated into heme-containing enzymes (e.g. cytochromes, catalase, and peroxidase), and $<0.2 \%$ is found circulating in the plasma bound to transferring [6].

There is no physiologic mechanism for iron excretion exists and only 1-2 mg of iron is lost each day as a result of sloughing of cells (i.e. from the mucosal lining of the gastrointestinal tract, skin, and renal tubules). Thus, normally iron loss and gain is in balance with the amount lost daily being equal to the amount absorbed daily.

Hepcidin is the principal regulator of plasma iron concentrations. It is a 25 amino acid hepatic peptide hormone that is synthesized in the liver, secreted into the blood, and systemically controls delivery of iron to blood plasma so as to meet cellular iron needs but avoid iron excess and toxicity. Hepcidin acts by binding to ferroportin on cell surfaces, inducing ferroportin internalization and degradation, and thereby blocking iron efflux into plasma from professional iron-exporting cells: hepatocytes, duodenal enterocytes, splenic and other macrophages and syncytiotrophoblasts [7].

The main cause of ID is poor dietary intake especially during periods of increased demand such as perinatal, toddlerhood, and adolescence. Symptoms of ID are not unique to ID (i.e. not pathognomonic). Iron is needed for many enzymes to function normally, so a wide range of symptoms may eventually emerge, either as the secondary result of the anemia, or as other primary results of ID. Signs of ID may include brittle nails, swelling or soreness of the tongue cracks in the sides of the mouth, an enlarged spleen, and frequent infections. Children who have ID may have an unusual 
craving for nonfood items, such as ice, dirt, paint, or starch. This craving is called pica [8].

Structural studies from autopsies and magnetic resonance imaging scanning have shown that iron distribution in the adult brain is heterogeneous and dependent on the stage of development. The basal ganglia, substantia nigra and deep cerebellar nuclei hold highest concentrations of iron in the adult brain. However, in children and adolescents, the highest concentrations are found in the globus pallidus, caudate nucleus, putamen, and substantia nigra with the highest concentrations being found at birth [9].

The timing of ID is therefore of great importance and it is important to consider "critical periods" of development that absolutely require adequate iron nutrition for "normal" development. In early life. there are three peak times of risk of ID, based on the balance of iron supply and demand - perinatal, toddlerhood and adolescence, the later particularly in females. Worryingly several human infant studies have shown that the effects of "early" ID on biological neural functioning are potentially irreversible [10].

\section{Stages of ID}

Three stages of ID have been described. The first stage of ID, known as iron depletion, occurs when iron stores are low and serum ferritin concentration drop. The second stage, iron-deficient erythropoiesis, occurs when iron stores are depleted and the body does not absorb iron efficiently. Iron-deficient erythropoiesis is characterized by a decrease in transferrin saturation and increases in transferrin receptor expression and free erythrocyte protoporphyrin concentration. IDA is the third and most severe stage of ID and is characterized by low $\mathrm{Hgb}$ and hematocrit values. Erythrocytes are hypochromic and microcytic during IDA and $\mathrm{Hgb}$ concentration falls below -2 standard deviations of the age- and sex-specific normal reference [11].

Assessment of an individual's iron status depends on measurement, interpretation and synthesis of various markers of iron metabolism. It is important to recognize that there is no single reliable marker of iron status, except at the extremes of deficiency and excess [12]. Microcytosis is most commonly associated with ID or thalassemic syndromes. An increase in the red-cell distribution width (RDW) may be an early indicator of a deficiency in iron even before anemia appears. Low serum ferritin is widely viewed as the best single laboratory indicator of iron depletion, the result must be interpreted with caution in any patient with an underlying inflammatory process, as ferritin is an acute phase reactant, and is increased when an acute or chronic inflammatory process is present [13].

Serum iron can be used as one test to evaluate patients for ID, especially in combination with iron binding capacity (transferrin and transferrin saturation). Serum iron alone is unreliable due to considerable physiologic variation in the results. Transferrin saturation $<15 \%$ is indicative of an ID state, either, latent ID, functional ID (usually associated with a decrease in transferrin but a disproportionately larger decrease in iron resulting in a transferrin saturation $<15 \%$ ) or true ID where a decrease in serum iron is associated with an increase in transferrin [14].

Primary prevention of ID is by dietary improvement and consumption of heme iron that is found in animal products such as red meat, fish, and poultry. Combine heme and non-heme iron rich foods when possible and include a source of vitamin $\mathrm{C}$ with meals helps iron absorption. Secondary prevention is by screening of infants with one or more risk factors for ID, this would allow for the treatment of ID in the pre-anemic stage, preventing IDA and its associated mental, motor and behavior effects [15].

\section{Aim of work}

The aim of our study is to assess iron status among apparently healthy toddlers and preschool children (from 1 year up to 6 years old) attending Assiut University Children Hospital.

\section{Subjects and Methods}

A cross-sectional study include 68 apparently healthy children (21 females and 47 males) aged 1-6 years old attending the outpatient clinics of Assiut University Children Hospital as well as pediatric surgical outpatient clinic during the period from January 1, 2015 to June 30, 2015 were involved in our study. Those children came for: Routine vaccination, for regular visits for checking growth and development and for minor surgical procedures. They were subjected to detailed history especially residence, mother educational level, dietetic history, history of recurrent acute, or chronic diseases and therapeutic history of iron supplement at the last 3 months or other drugs that affect iron metabolism. For each patient, the following investigations were done:

1. Complete blood count including reticulocyte count

2. Serum iron

3. Total iron binding capacity (TIBC)

4. Serum ferritin

5. Transferrin saturation.

Written consent was taken from parents of each child involved in our study in addition for iron therapy for those having ID. All steps of this research were approved by the research ethics committee of Assiut University. Children considered being non-anemic if their Hgb levels above cutoff point established by the World Health Organization (WHO) 2001 [16]. 


\section{Statistical analysis}

Results were presented as Mean \pm 2 SD, Normally distributed data was analyzed using Chi-square test and analysis of variance. SPSS was used for correlation coefficient analysis and to evaluate the relationship between the variables. Results are presented in tables.

\section{Results}

Table 1 shows that the frequency of abnormal iron indices in the studied group where low serum ferritin (as the most sensitive and reliable marker for ID) was detected in $41.2 \%$ of our studied apparently healthy children with normal Hgb level.

Table 1: The frequency of abnormal iron indices in the studied group

\begin{tabular}{ll}
\hline Item & Frequency (\%) \\
\hline $\begin{array}{l}\text { Serum Iron } \\
\quad \text { Decrease }<40 \mu \mathrm{g} / \mathrm{dl}\end{array}$ & $14(20.59)$ \\
TIBC & $18(26.47)$ \\
$\quad$ Increase $>410 \mu \mathrm{g} / \mathrm{dl}$ & \\
$\begin{array}{l}\text { Ferritin } \\
\quad \text { Decrease }<12 \mathrm{ng} / \mathrm{ml}\end{array}$ & $28(41.2)$ \\
Transferrin saturation & $32(47)$ \\
$\quad$ Decrease $<15 \%$ &
\end{tabular}

Table 2 shows that the percentage of abnormal microscopic findings of red blood cells (RBCs) (in blood film) in the studied group where hypochromasia, microcytosis, anisocytosis, and poikilocytosis were detected in our studied cases.

Table 2: Percentage of abnormal microscopic findings of RBCs (in blood film) in the studied group

\begin{tabular}{ll}
\hline RBCs finding & "n = 68" (\%) \\
\hline Hypochromasia (MCH < 24pg) & $14(20.59)$ \\
Microcytosis (MCV < 75fl) & $28(41.17)$ \\
Anisocytosis (RDW > 15\%) & $22(35.29)$ \\
Poikilocytosis & $22(35.29)$ \\
\hline RBC: Red blood cell, MCH: Mean corpuscular hemoglobin, MCV: Mean corpuscular volume, RDW: & \\
Red-cell distribution width. &
\end{tabular}

Table 3 shows that the frequency of ID in relation to age in studied groups where ID was significantly increased among lower age group from 1 to 3 years old $(p<0.05)$.

Table 3: Iron deficiency in relation to age in studied groups

\begin{tabular}{llll}
\hline Item & $1-3$ years & $>3-6$ years & $p$-value \\
\hline Iron deficient $(\%)$ & $17(39.5)$ & $11(44.0)$ & $\mathrm{p}<0.05^{*}$ \\
Non-iron deficient (\%) & $26(60.5)$ & $14(56.0)$ & \\
\hline${ }^{*}$-value significant $<0.05$. & & &
\end{tabular}

Table 4 shows that the frequency of ID in relation to sex in studied children where more than half of males $(51.2 \%)$ had ID versus only $(19 \%)$ in females with significance difference between male and female $(p<0.001)$. Table 5 shows that ID was significantly higher in rural children than urban $(p<$ 0.001).

Table 4: Iron deficiency in relation to sex in studied group

\begin{tabular}{llll}
\hline Item & Female & Male & p-value \\
\hline Iron deficient (\%) & $4(19.0)$ & $24(51.1)$ & $\mathrm{p}<0.01^{*}$ \\
Non-iron deficient (\%) & $17(81)$ & $23(48.9)$ & \\
\hline${ }^{*}$ p-value significant $<0.01$. & & &
\end{tabular}

\section{Discussion}

ID is the most common form of malnutrition worldwide and according to the WHO/UNICEF (2003) estimates $40-50 \%$ of children $<5$ years in developing countries are iron deficient. ID may lead to delay in infant's motor (activity and movement) or mental function (normal thinking and processing skills). Management is targeted to the most vulnerable age group (preschool age) for early intervention before progress to IDA that will lead to irreversible defects of cognitive and intellectual functions of the child [3]. According to the WHO Hgb considered to be normal when its level $\geq 11 \mathrm{~g} / \mathrm{dl}$, below which cases were excluded as having anemia. ID is defined by serum Iron $<40 \mathrm{mcg} / \mathrm{dl}$, TIBC $<410 \mathrm{mcg} / \mathrm{dl}$, serum ferritin $<12 \mathrm{ng} /$ $\mathrm{ml}$, and transferrin saturation $<15 \%$ [16].

Table 5: Iron deficiency in relation to residence in studied group

\begin{tabular}{llll}
\hline Item & Rural & Urban & $\mathrm{p}$-value \\
\hline Iron deficient (\%) & $23(51.11)$ & $5(21.73)$ & $\mathrm{p}<0.001^{* *}$ \\
Non-iron deficient (\%) & $22(57.78)$ & $18(78.27)$ & \\
\hline${ }^{*}$-value significant $<0.001$. & & &
\end{tabular}
${ }^{*} \mathrm{p}$-value significant $<0.001$

The WHO (2001) stated that serum ferritin level is the most specific biochemical test that correlates with relative total body iron stores. Accordingly in our study, ID, diagnosed by low serum ferritin, was detected in $41.2 \%$ of our studied children with normal Hgb levels. This add more to the already present major health problem of IDA in Egypt that affect $>40 \%$ of children under 5 years of age increasing the risk of long-term effects of both ID and IDA on cognition and intellectual functions of these child [17]. These finding agree in part with the National Health and Nutrition Survey in Mexico (2006) where low iron stores were present in $32 \%$ of children $12-24$ months of age and tissue ID in $19 \%$ of the same group [18]. Data from India indicates that $70-90 \%$ of children $6-59$ months of age may be iron deficient, with prevalence even higher in those $<2$ years of age [19]. Tuohy et al., 1994 studied ID in preschool children in New Zealand and stated that a quarter of those under 3 years of age having low iron; these results may be explained by the fact that children at this age go through spurts of rapid growth, which requires a great deal of iron. A balanced diet, with adequate amounts of iron is important at these times [20].

Microcytosis was observed (mean corpuscular volume $[\mathrm{MCV}]<75 \mathrm{fl}$ ) in $41.18 \%$, hypochromasia (Mean corpuscular $\mathrm{Hbb}[\mathrm{MCH}]<24 \mathrm{pg}$ ) in $20.59 \%$ and anisocytosis (RDW $>15 \%$ ) in $35.29 \%$ of our studied children. In ID states, RBCs are continuously produced in the bone marrow as the iron stores progressively decrease. As a result, they tend to be more and more microcytic. Long life span of RBCs, approximately 4 months, results in several cohorts of normocytic and increasingly microcytic RBCs coexist in the peripheral blood, leading to anisocytosis. Moreover, ID leads also to poikilocytosis (variations in RBC shape), which also increases the width of RBCs [21]. 
As regard the risk factors of ID in our study, all parameters of ID (decrease serum Iron, increased TIBC, low serum ferritin, and transferrin saturation) were significantly higher in the age group (1-3 years old) and this finding agree in part with the National Health and Nutrition Survey in Mexico (2004), where low iron stores was found in $32 \%$ of children 12-24 months of age and tissue ID in $19 \%$ of the same group [22]. Data from Indonesia indicates that $70-90 \%$ of children 6-59 months of age may be iron deficient, with prevalence even higher in those under 2 years of age [19], also Crampton et al., (1994) found that ID in preschool children in New Zealand is a cause for concern, with up to a quarter of those under 3 years of age having low iron, these results may be explained by the fact that children at this age go through spurts of rapid growth, which requires a great deal of iron. A balanced diet, with adequate amounts of iron is important at these times [20].

In our study, ID is significantly higher among males than females. Our results agree with a study made on Palestinian children age 2-5 years showed that boys were more susceptible to this deficiency than girls, sex differences in feeding practices were observed in that study indicated that male children were breastfed for a longer period than female children, girls consumed more complementary foods than breast milk [23]. More consumption of junk foods, due to outdoor playing for long time, in addition to poor food diversity with consumption of large amounts of cow's milk, especially in rural areas, can contribute to ID and IDA in these children.

In our study, there were significant abnormal iron parameters in rural children than urban one. This agree with a population-based study of Indonesian children found that $54 \%$ of urban children $6-24$ months and $57 \%$ of their rural counterparts suffered from ID [19]. Our results can be explained by the fact that males consuming much junk foods due to playing outdoors in contrast to females in addition to more consumption of cow's milk as families pay more attention to males and give them cow's milk which is much available in rural areas and considered as a poor source of iron plus affection of iron absorption that leads to ID.

\section{Conclusion}

Asymptomatic ID was detected in $41.2 \%$ of our studied children with normal Hgb levels. Normal Hgb doesn't exclude ID. Serum ferritin $<12 \mathrm{ng} / \mathrm{dl}$ is the most reliable indicator of ID. MCV $<75 \mathrm{fl}$ and $\mathrm{RDW}>15 \%$ are good indicators of ID even before appearance of anemia. Male gender, low socioeconomic status, residency in rural areas, maternal illiteracy, poor dietary diversity, and consumption of junk foods are the main risk factors contributed in ID and consequently IDA in Egyptian infants and children.

\section{Author Contribution}

- $\quad$ Fardos H. Abd El Aal and Osama M. El-Asheer and Khalil Abdel Khalek Mohamed suggesting this study, study design, writing of the paper, collection of sample and interpretation of data Madleen A. A. Abdou do all Laboratory study for our studied children

Mary S. Naeem do statistical analysis of data, sample collection in addition to share in writing.

\section{References}

1. Georgieff M. Long-term brain and behavioral consequences of early iron deficiency. Nut Rev. 2011;69 Suppl 1:S43-8. https:// doi.org/10.1111/j.1753-4887.2011.00432.x

\section{PMid:22043882}

2. Sherry B, Mei Z, Yip R. Continuation of the decline in prevalence of anemia in lowincome infants and children in five states. Pediatrics. 2001;107(4):677-82. https://doi.org/10.1542/ peds.107.4.677

PMid:11335743

3. Lozoff B, Jimenez E, Smith JB. Double burden of iron deficiency in infancy and low socioeconomic status: A longitudinal analysis of cognitive test scores to age 19 years. Arch Pediatr Adolesc Med. 2006;160(11):1108-13. https://doi.org/10.1001/ archpedi.160.11.1108

PMid: 17088512

4. Ram RS, Bernath PF. Fourier transform emission spectroscopy of the $\mathrm{g}^{4} \Delta-\mathrm{a}^{4} \Delta$ system of FeCl. J Mol Spectrosc. 2003;221(2):261. https://doi.org/10.1016/s0022-2852(03)00225-x

5. Hurrell RF, Reddy M, Cook JD. Inhibition of non-haem iron absorption in man by polyphenolic-containing beverages. $\mathrm{Br} J$ Nutr. 1999;81(4):289-95. https://doi.org/10.1017/ s0007114599000537 PMid:10999016

6. Zhang AS, Enns CA. Molecular mechanisms of normal iron homeostasis. Hematology Am Soc Hematol Educ Program. 2009;2009(1):207-14.

PMid:20008200

7. Nemeth E, Tuttle MS, Powelson J, Vaughn MB, Donovan A, Ward DM, et al. Hepcidin regulates cellular iron efflux by binding to ferroportin and inducing its internalization. Science. 2004;306(5704):2090-3. https://doi.org/10.1126/ science. 1104742

PMid:15514116

8. Beard JL. Iron biology in immune function, muscle metabolism and neuronal functioning. J Nutr. 2001;131(2S-2):568S-79S; discussion 580S. https://doi.org/10.1093/jn/131.2.568s PMid: 11160590

9. Logan S, Martins S, Gilbert R. Iron therapy for improving psychomotor development and cognitive function in children under the age of three with iron deficiency anemia. 
Cochrane Database Syst Rev. 2001;2:CD001444. https://doi. org/10.1002/14651858.cd001444

\section{PMid:11405989}

10. Georgieff MK. The role of iron in neurodevelopment: Fetal iron deficiency and the developing hippocampus. Biochem Soc Trans. 2008;36(6):1267-71. https://doi.org/10.1042/bst0361267 PMid:19021538

11. Allen LH. Anemia and iron deficiency: Effects on pregnancy outcome. Am J Clin Nutr. 2000;71 Suppl 5:1280S-4S. PMid:10799402

12. SCAN (Scientific Advisory Committee on Nutrition). Iron and Health, London TSO; 2010. p. 37.

13. Arosio $P$, Levi $S$. Ferritin, iron homeostasis, and oxidative damage. Free Radic Biol Med. 2002;33(4):457-63.

PMid:12160928

14. Irwin Gross. Laboratory Studies in the Diagnosis of Iron Deficiency, Latent Iron Deficiency and Iron Deficient Erythropoiesis. Eastern Maine Medical Center; 2004.

15. Baker RD, Greer FR, Committee on Nutrition American Academy of Pediatrics. Diagnosis and prevention of iron deficiency and iron-deficiency anemia in infants and young children (0-3 years of age). Pediatrics. 2010;126(5):1040-50. https://doi.org/10.1542/peds.2010-2576 PMid:20923825

16. World Health Organization. Iron deficiency Anemia: Assessment, Prevention and Control: A Guide for Programme Managers. Geneva, Switzerland: UNICEF, United Nations University, World Health Organization; 2001.

17. World Health Organization. WHO Global Estimates of the
Prevalence of Anaemia in Infants and Children aged 6-59 Months. Geneva: World Health Organization; 2011.

18. Morales-Ruan Mdel C, Villalpando S, Garcia-Guerra A, ShamahLevy T, Robledo-Perez R, Avila-Arcos MA, et al. Iron, zinc, copper and magnesium nutritional status in Mexican children aged 1 to 11 years. Salud Publica Mex. 2012;54(2):125-34. https://doi.org/10.1590/s0036-36342012000200008 PMid:22535171

19. Sandjaja S, Budiman B, Harahap H, Ernawati F, Soekatri M, Widodo $\mathrm{Y}$, et al. Food consumption and nutritional and biochemical status of 0.5-12-year-old Indonesian children: The SEANUTS study. Br J Nutr. 2013;110 Suppl 3:S11-20. https:/ doi.org/10.1017/s0007114513002109

PMid:24016762

20. Crampton $P$, Farrell $A$, Tuohy $P$. Iron deficiency anaemia in infants. N Z Med J. 1994;107(972):60-1. PMid:8115073

21. Handin RJ, Lux SE, Stossel TP. Blood: Principles and Practice of Hematology. $2^{\text {nd }}$ ed. Philadelphia, PA: Lippincott Williams and Wilkins; 2003. p. 2304

22. Summary Report of an International Technical Workshop. Cuernavaca, Mexico: Flour Fortification Initiative. Wheat Flour Fortification: Current Knowledge and Practical Applications; 2004.

23. El Kishawi RR, Soo KL, Abed YA, Wan Muda WA. Anemia among children aged 2-5 years in the Gaza Strip-Palestinian: A cross sectional study. BMC Public Health. 2015;15:319. https://doi.org/10.1186/s12889-015-1652-2

PMid:25879619 